\title{
Investigating the Hysteretic Behavior of Concrete-Filled Steel Tube Arch by Using a Fiber Beam Element
}

\author{
Jun Ma, Yang Liu, Qingfei Gao, and Kang Hou \\ School of Transportation Science and Engineering, Harbin Institute of Technology, Harbin 150090, China \\ Correspondence should be addressed to Kang Hou; hk6560@163.com
}

Received 30 September 2014; Accepted 21 January 2015

Academic Editor: P. Balasubramaniam

Copyright (C) 2015 Jun Ma et al. This is an open access article distributed under the Creative Commons Attribution License, which permits unrestricted use, distribution, and reproduction in any medium, provided the original work is properly cited.

\begin{abstract}
A fiber beam finite element that could account for the nonlinear constitutive relationship between steel and concrete was applied to investigate the hysteretic behavior of concrete filled steel tube (CFT) arch ribs of bridges. At first, the effectiveness of this fiber beam element using for nonlinear analysis was verified by comparing the analytical results with the experimental data, and then this composite element was applied to analyze the hysteretic performance of CFT arch ribs. The following hysteretic behavior of CFT arch ribs of bridges was investigated such as the hysteretic behaviors of moment-curvature of arch ribs in vertical direction of bridge and the hysteretic relationship between load and displacement of arch ribs in longitudinal and transverse direction of bridge. Finally, some parameters affecting the hysteretic behaviors of CFT arch ribs were presented by evaluating the capacity of ductility of CFT arch ribs.
\end{abstract}

\section{Introduction}

The CFT components are widely used as the arch ribs of the long span arch bridges [1-3]. Since the long span CFT arch bridges are always acted by the long-term reduplicative dynamic loads such as the traffic load, wind load, and temperature load, it is inevitable for the CFT arch ribs to generate some nonlinear behavior during the life cycle. Some researchers paid attention to the nonlinear performance of CFT components. Han [4] proposed a simplified restoring force model in moment-curve and load-displacement model of CFT structures. Zhong [5] analyzed the hysteretic behavior of linear type CFT component under the reduplicative loads, and then a dual interface constitutive model was presented. Hajjar [6] analyzed the hysteretic behavior of single layer CFT frame under the reduplicative loads in the plane and built a restoring force model of CFT frame. Aval [7] presents the development of a comprehensive composite beam-column fiber element implemented to investigate the effect of bond between the concrete core and the steel shell on the inelastic behavior of CFT columns. Lv et al. [8] researched the hysteretic behavior of thin-walled CFT columns with large cross sections by means of FEM method. With the experimental researches [9-12], the hysteretic behaviors of CFT columns and connections were also improved. The researchers also analyzed the dynamic behaviors of CFT arch bridges [8,13-15]. For the CFT arch ribs, however, it was hardly to build a unitive restoring force model adapting threedimension because the geometric shapes of arch ribs are always spatial asymmetry. It is effective to solve this issue by using the nonlinear finite element analysis. Therefore, this study investigates the hysteretic performance of CFT arch ribs of long-span bridges by using the fiber beam finite element.

\section{Generation and Experimental Verification of the Finite Element Model}

To analyze the nonlinear performance of arch ribs, it is necessary to determine the constitutive relationship between steel and core concrete of ribs under the action of the reduplicative load [16]. In this section, the detail of the constitutive model between core concrete and steel is described firstly, and then the fiber beam finite element model is generated. Finally, the effectiveness of the generated finite element model is demonstrated by comparing the analytical results with the experimental data. 
2.1. Stress-Strain Relationship between Steel and Concrete. In this study, the bilinear kinematic hardening model is applied to simulate the relationship between core concrete and steel. This constitutive model includes the Bausinger Effect and Mises Yield Criteria as shown in Figure 1 (herein, $E_{e}$ and $E_{p}$ represent Young's modulus of steel and the modulus of steel in hardening phase, resp.).

For the core concrete CFT arch ribs, the stress-strain relationships when the core concrete is acted under pressure are defined as follows [9]:

$$
\sigma= \begin{cases}\frac{\sigma_{0}\left(\varepsilon / \varepsilon_{0}\right) r}{r-1+\left(\varepsilon / \varepsilon_{0}\right)^{r}}, & \varepsilon \leq \varepsilon_{0} \\ \sigma_{0}(1-q)+\sigma_{0} q\left(\frac{\varepsilon}{\varepsilon_{0}}\right)^{0.1 \xi}, & \varepsilon>\varepsilon_{0}, \quad \xi \geq 1.12 \\ \frac{\sigma_{0}\left(\varepsilon / \varepsilon_{0}\right)}{\beta\left(\left(\varepsilon / \varepsilon_{0}\right)-1\right)^{f_{c k} / 30}+\left(\varepsilon / \varepsilon_{0}\right)}, & \varepsilon>\varepsilon_{0}, \quad \xi<1.12,\end{cases}
$$

where $\sigma_{0}, \varepsilon_{0}, \beta, \xi, r, q, E_{c}$, and $E_{\text {sec }}$ are defined as

$$
\begin{gathered}
\sigma_{0}=f_{c k}\left[1.194+\left(\frac{13}{f_{c k}}\right)^{0.45}\left(-0.07485 \xi^{2}+0.5789 \xi\right)\right], \\
\varepsilon_{0}=100 \times\left[13+3\left(\frac{f_{c k}}{20}\right)+\left(4+8\left(\frac{f_{c k}-20}{20}\right)\right) \xi^{0.2}\right], \\
q=\frac{0.1 \xi^{0.745}}{0.2+0.1 \xi}, \\
\beta=\left(2.36 \times 10^{-5}\right)^{\left[0.25+(\xi-0.5)^{7}\right]} \times 5.0 \times f_{c k}^{2} \times 10^{-4}, \\
\xi=\alpha \frac{f_{y}}{f_{c k}}, \\
r=\frac{E_{c}}{E_{c}-E_{\mathrm{sec}}} \\
E_{\mathrm{sec}}=\frac{\sigma_{0}}{\varepsilon_{0}} \times 10^{6} .
\end{gathered}
$$

When the core concrete are acted under tension, the stressstrain relationships are defined by

$$
\sigma= \begin{cases}\sigma_{p}\left[1.2\left(\frac{\varepsilon}{\varepsilon_{p}}\right)-0.2\left(\frac{\varepsilon}{\varepsilon_{p}}\right)^{6}\right], & \varepsilon \leq \varepsilon_{p} \\ \sigma_{p}\left(\frac{\varepsilon}{\varepsilon_{p}}\right) \frac{1}{0.51 \sigma_{p}^{2}\left(\varepsilon / \varepsilon_{p}-1\right)+\varepsilon / \varepsilon_{p}}, & \varepsilon>\varepsilon_{p},\end{cases}
$$

where $\sigma_{p}$ and $\varepsilon_{p}$ are defined as the following two equations:

$$
\begin{gathered}
\sigma_{p}=0.26\left(1.25 f_{c k}\right)^{2 / 3}, \\
\varepsilon_{p}=43.1 \sigma_{p}(\mu \varepsilon),
\end{gathered}
$$

where $f_{c k}$ is the compressive strength of concrete and $f_{y}$ represents the yield limit of steel material.

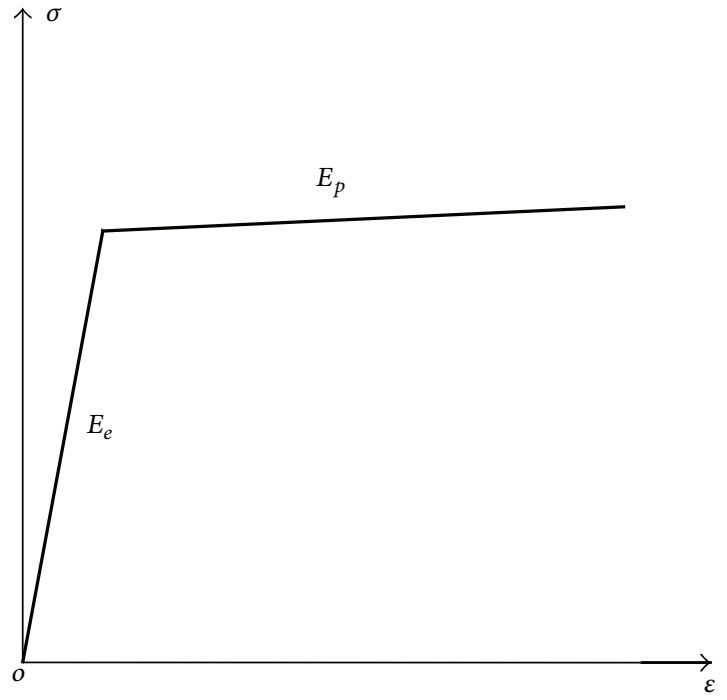

FIGURE 1: Stress-strain relationship of steel material.

2.2. Generation of the Finite Element Model. The fiber beam finite element is utilized to simulate the nonlinear performance of CFT arch ribs. Here, we only consider the circular section of steel tube since this section is the most popular type for practical long span arch bridges. As shown in Figure 2, an example is taken, and, in the radial direction, the steel tube is divided into one part and the concrete was equally divided into 10 items. Along the arc length, the steel tube and concrete are equally divided into 20 parts. After the meshing process, there are total 20 steel elements and 100 concrete elements. For the axial compression components, all the concrete elements resist the compression, and for the compress-bending components, half of the concrete section resists the compression and the rest half of concrete section resists the tension. A section of finite element model built by the ANSYS software is shown in Figure 2(c), and the finite element model of the whole CFT arch rib (calculating span $L$ is $460 \mathrm{~cm}$, and arch axis equation takes the parabolic function. Net rise is $153.3 \mathrm{~cm}$, and rise span ratio takes $1 / 3$. $f_{c k}$ takes $36.8 \mathrm{MPa}$ and $f_{y}$ goes to $307.67 \mathrm{MPa}$ ) is shown in Figure 3.

2.3. Verification of the Generated Finite Element Model. In order to verify the effectiveness of the generated finite element model, the analytical results are compared with the experimental data. During the iterative calculation, the geometrical nonlinear of the arch ribs is considered, and the NewtonRaphson method is applied to solve the incremental equation at each iteration. Here, the monotonous load and cyclic load are taken into account. The material properties of the core concrete of CFT arch ribs are assigned depending on whether the section resists tension or compression.

In one case, the hysteretic relationship between load and displacement of the CFT arch rib under the action of reduplicative load (diameter, thickness, and span of this arch rid take $108 \mathrm{~mm}, 5 \mathrm{~mm}, 1200 \mathrm{~mm}$, resp. The concrete compression strength and the yield limit of steel take $33.8 \mathrm{MPa}$ 


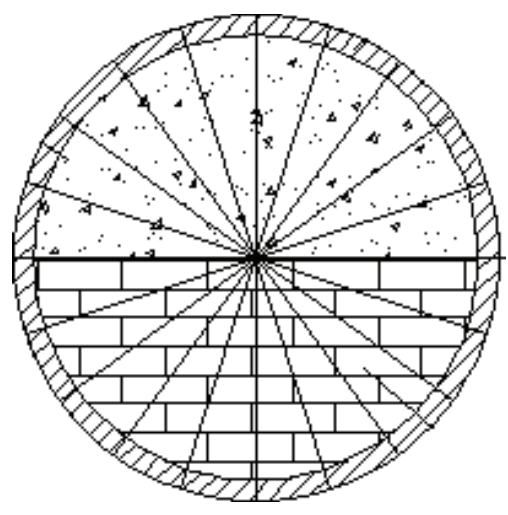

(a) Nonaxial compression section

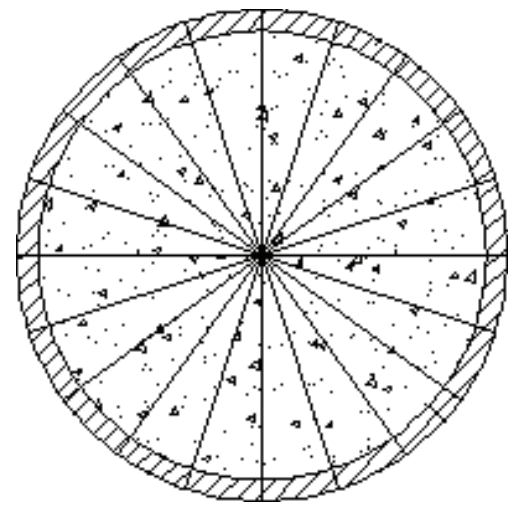

(b) Axial compression section

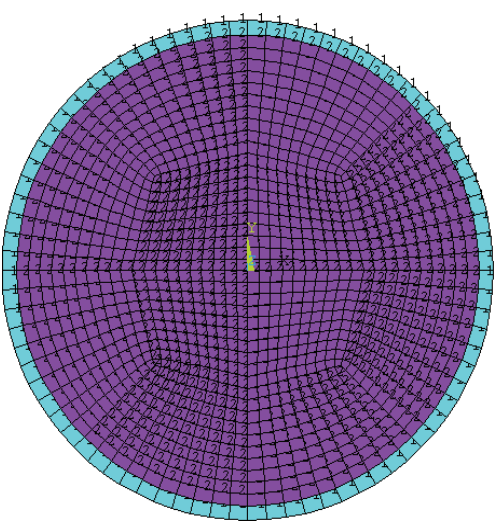

(c) Section model after meshing

FIGURE 2: Finite element model of the section of CFT arch rib.

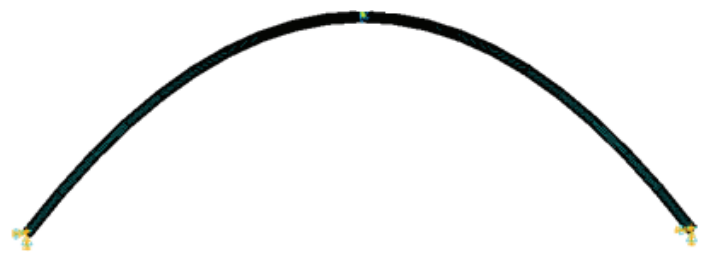

FIGURE 3: FEM model of the CFT arch rib.

and $327.8 \mathrm{MPa}$, resp.) is calculated by the generated finite element model. The comparison of hysteretic curves between analytical results and experimental data is shown in Figures 4 and 5, respectively. In another case, the hysteric performance of the CFT arch rib (as shown in Figure 3) is supposed to be acted by the monotonous load. The load-displacement curves of the CFT arch rib are shown in Figures 6 and 7. From above comparisons, the results obtained by finite element model fit well with the experimental results.

\section{Results and Discussion}

In this section, we investigate three types of hysteretic behaviors of the CFT arch ribs, that is, the hysteretic behaviors of moment-curvature of arch ribs in vertical direction of bridge and the hysteretic relationship between load and displacement of arch ribs in longitudinal and transverse direction. For convenience, the example utilized in last section is also taken in this part. The simplified analytical models of arch ribs are shown in Figure 8.

3.1. Hysteretic Behaviors of Moment-Curvature of Arch Ribs. As shown in Figure 8(a), the arch rib stays in the compression-bending state under the action of the vertical reduplicative load. The fiber beam element is applied to build the arch rib, and the hysteretic relationship between moment and curvature of the top part of arch rib is investigated numerically. The hysteretic curve shown in Figure 9 is close to plump shape and this hysteretic curve has no significant pinch phenomenon. The results show that the hysteretic

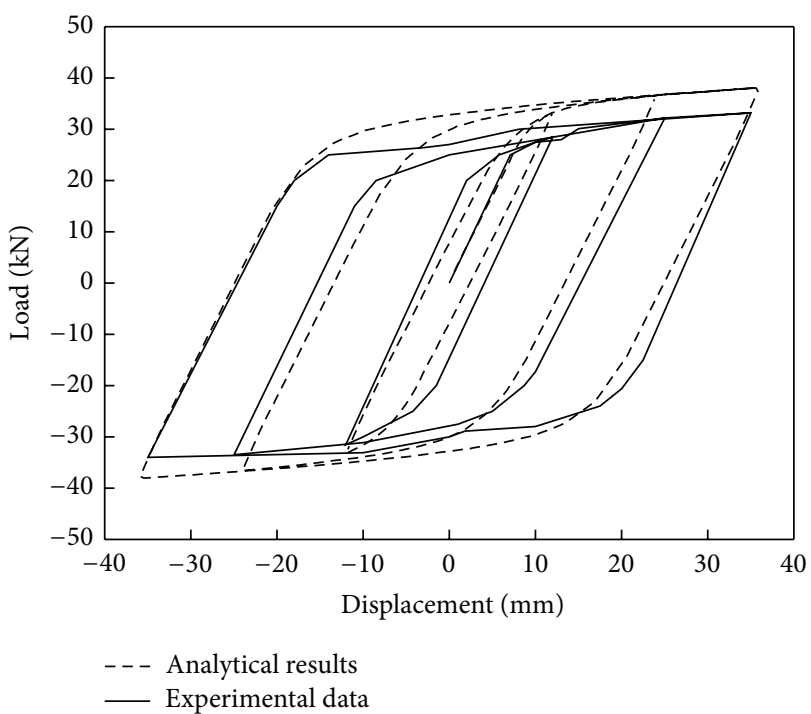

FIGURE 4: Comparison of the hysteretic curve between analytical results and experimental data (maximum load is $20 \mathrm{kN}$ ).

relationship of CFT arch ribs is similar to the hysteretic performance of CFT column. The hysteretic curve of momentcurvature is directly related to the following factors, that is, the steel amount ratio of CFT arch ribs $\alpha$, the yield limit of steel material $f_{y}$, the compressive strength of concrete $f_{c k}$, and the initial stress. The arch span $L$ and arch rise span ratio $f$ have no significant effect on the hysteretic performance.

3.2. Load-Displacement Hysteretic Behavior in the Longitude Direction of Bridge. When the dynamical load acts on the top part of arch rib (Figure 8(b)), the load-displacement hysteretic curve in the longitude direction of bridge is similar to the one obtained in last section as shown in Figure 10. The main factors that affect the hysteretic performance of CFT rib are discussed in detail as follows.

3.2.1. Steel Amount Ratio of CFT Arch Rib $\alpha$. An example is taken for investigating the effect of the steel amount ratio of 


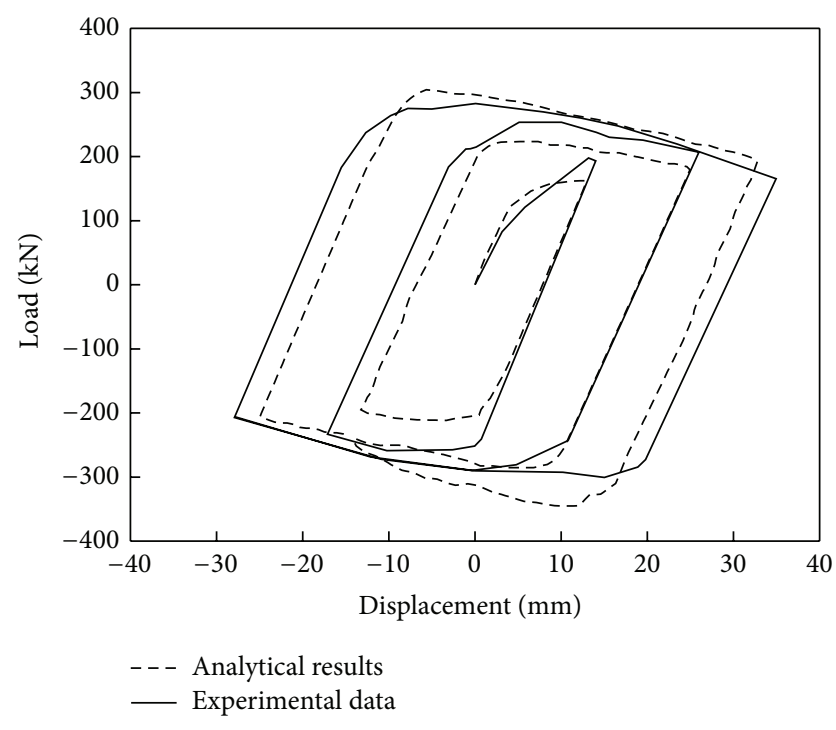

Figure 5: Comparison of the hysteretic curve between analytical results and experimental data (maximum load is $250 \mathrm{kN}$ ).

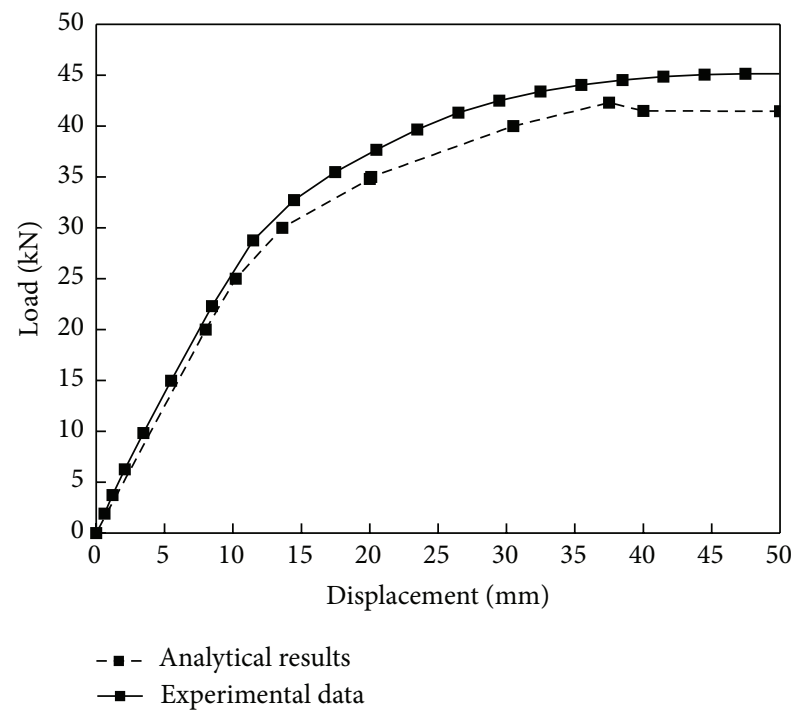

Figure 6: Comparison of the load-displacement curve between analytical results and experimental data (1/2 span).

CFT arch rib $\alpha$ on the hysteretic performance. The detailed parameters of this arch rib are described as follows. The diameter of $\operatorname{arch}$ rib $D$, the thickness of the tube, the span length of the arch $L$, the rise span ratio $f$, the yield limit of steel material $f_{y}$, and the compressive strength of core concrete $f_{c u}$ take $76 \mathrm{~mm}, 3.79 \mathrm{~mm}, 4600 \mathrm{~mm}, 1 / 3,307.8 \mathrm{MPa}$, and $36.8 \mathrm{MPa}$, respectively. Here, we consider the changing range of $\alpha$ from 0.101 to 0.234 . The comparison of the hysteretic performance considering different value of $\alpha$ is shown in Figure 11. According to Figure 11, the stiffness and load bearing capacity of the CFT arch rib increased obviously in the elastic stage as the value of $\alpha$ goes up, and this increasing trend goes to stable gradually in the hardening stage.

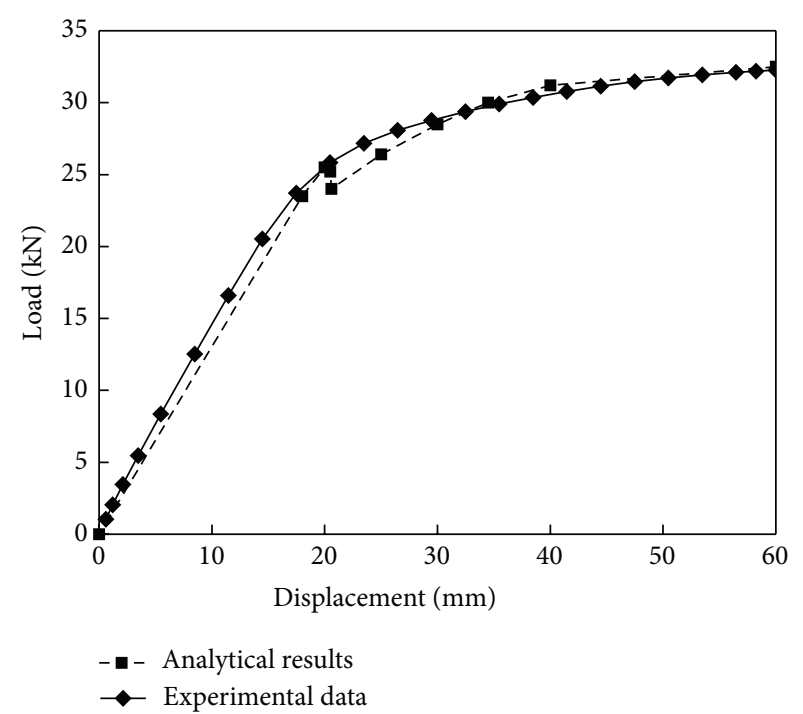

FIgURE 7: Comparison of the load-displacement curve between analytical results and experimental data (1/4 span).

3.2.2. Yield Limit of Steel Material $f_{y}$. With the same example used in Section 3.2.1, the comparison of load-displacement curve of CFT arch rib in the longitude direction of bridge between different yield limit of steel material is shown in Figure 12. When the yield limit of steel material takes different value, the similar changing trends of the stiffness of CFT arch rib are found out. For one certain $f_{y}$, the stiffness of CFT arch rib goes up linearly in the elastic phase and goes to stable in the hardening phase.

3.2.3. Arch Rise Span Ratio f. It could obviously conclude from Figure 13 that, for one certain rise span ratio, the load bearing capacity and the stiffness of the CFT arch rib increase both in elastic stage and hardening stage as the value of rise span ratio $f$ goes up. There are similar changing trends of the load-displacement hysteretic curve as the arch takes different rise span ratio $f$.

3.2.4. Span Tube Diameter Ratio g. As shown in Figure 14, the stiffness and the load bearing capacity of the CFT arch rib decrease as the increasing of the value of span tube diameter ratio $g$. For each certain value of $g$, the changing trend of stiffness of CFT arch rib is similar to the effect of rise span ratio $f$.

3.2.5. Arch Shape. There are three types of popular arch shapes of arch bridge, that is, parabola shape, arc shape, and catenary shape. As shown in Figure 15, the parabola shape arch and catenary shape arch have the similar effect on the stiffness and load bearing capacity in longitude direction of bridge, and the arc shape arch has the worst effect on the hysteretic performance compared with the other two types of arch shape.

3.2.6. Axial Compression Ratio $n$. The axial compression ratio $n$ is defined as the ratio of initial vertical pressure to 


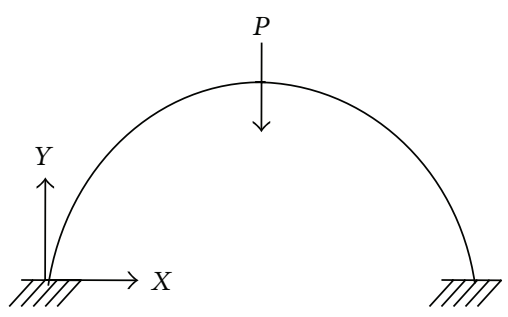

(a) Vertical loads

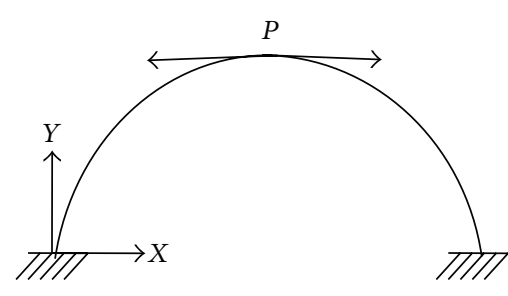

(b) Longitude loads

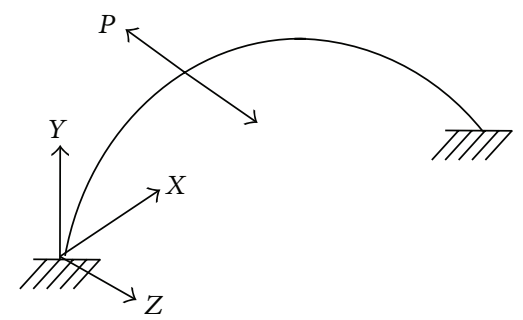

(c) Transverse loads

FIgURE 8: Simplified analytical models of arch rib.

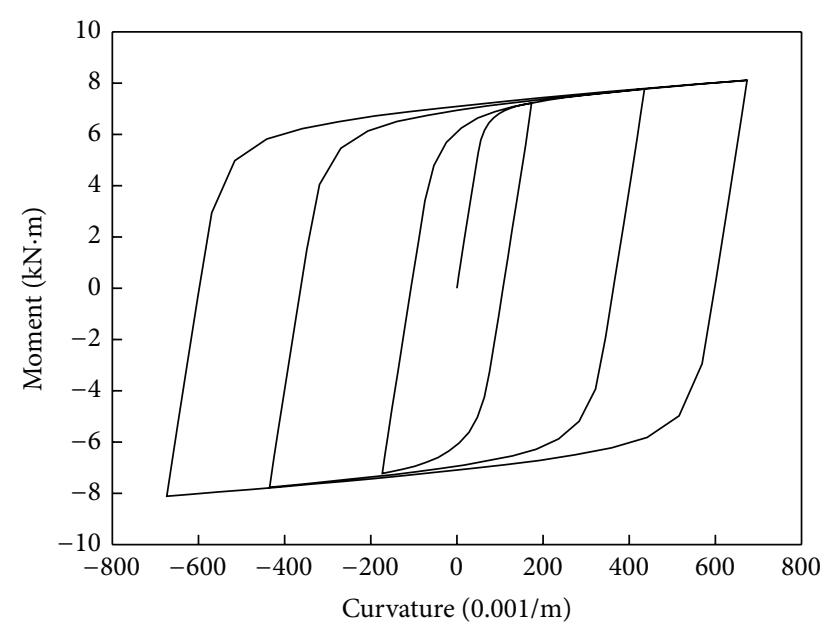

Figure 9: Hysteretic curve of moment-curvature of the CFT arch rib.

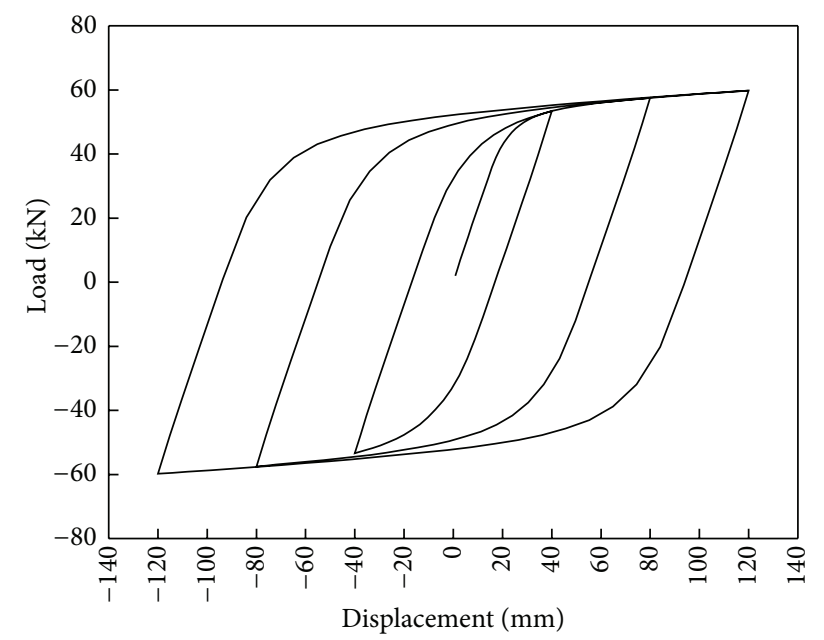

FIGURE 10: Load-displacement hysteretic curves of CFT arch rib in the longitude direction of bridge.

the critical pressure. The effects caused by the ratio $n$ to the load-displacement curve of parabola shape CFT arch rib are shown in Figure 16. The ratio $n$ has no obvious effect on the stiffness of CFT arch rib in elastic stage; however, the load bearing capacity and the stiffness decrease in the hardening

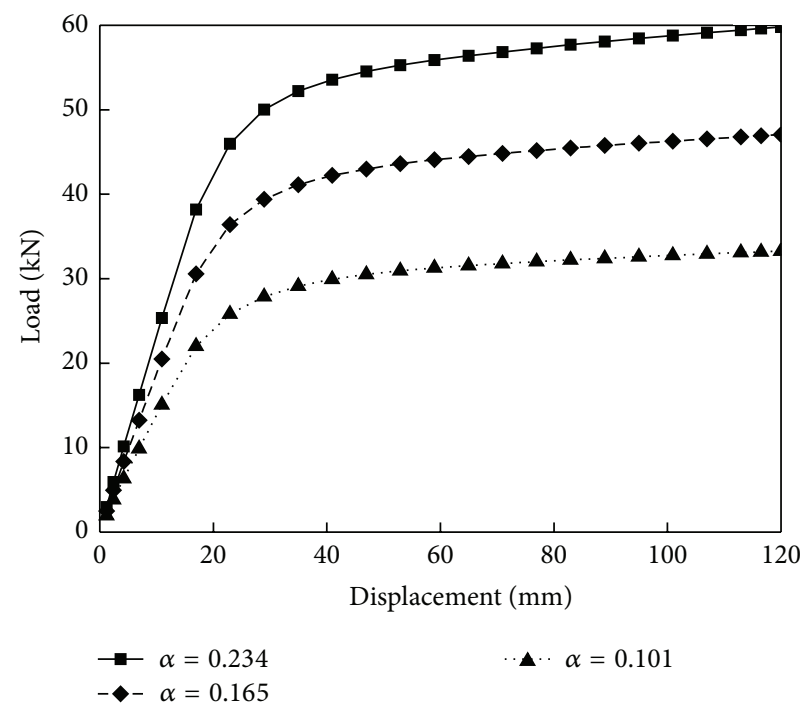

FIGURE 11: Load-displacement hysteretic curves of CFT arch rib considering different value of $\alpha$.

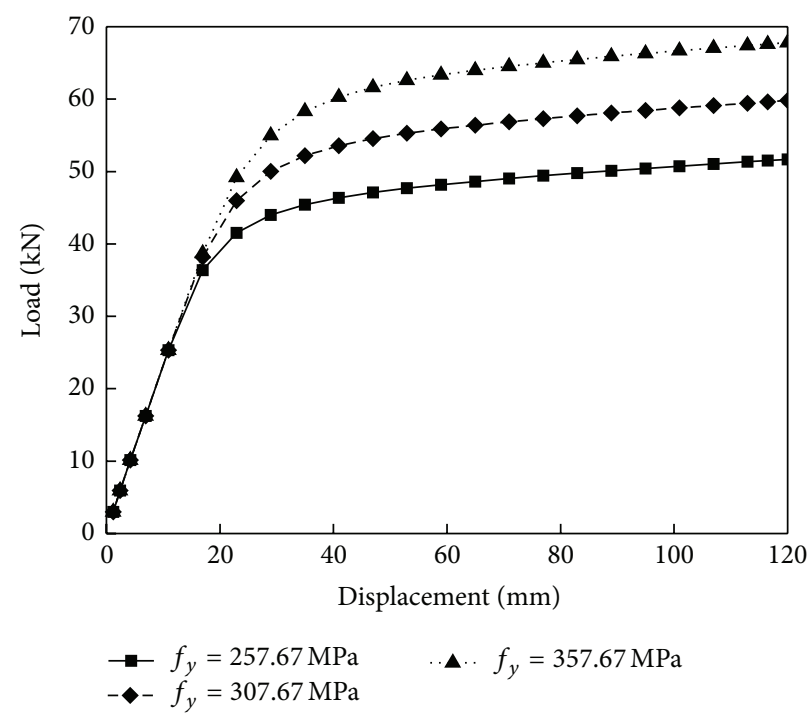

FIGURE 12: Load-displacement hysteretic curves of CFT arch rib considering different value of $f_{y}$. 


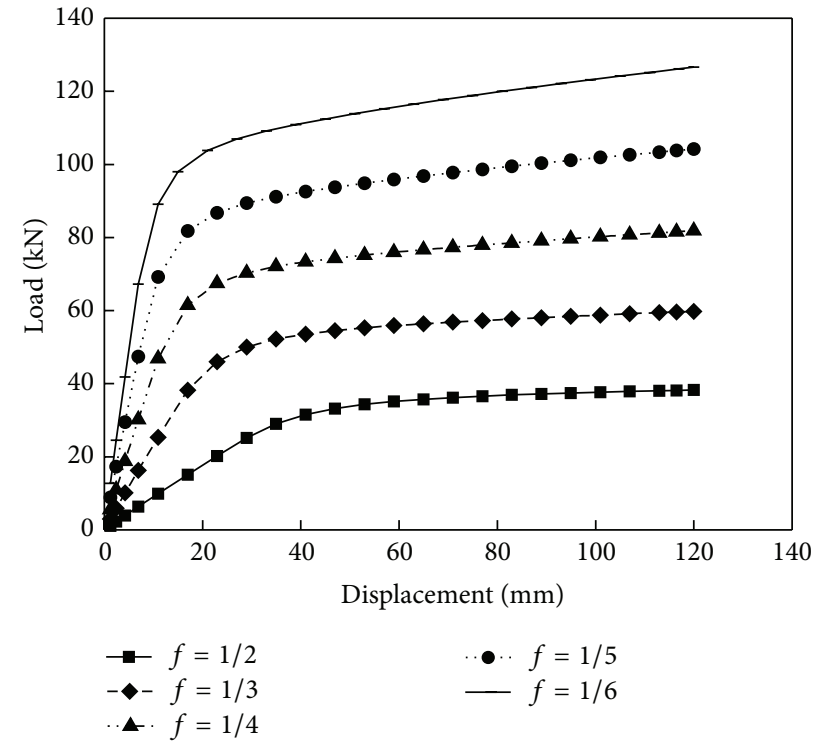

Figure 13: Load-displacement hysteretic curves of CFT arch rib considering different value of $f$.

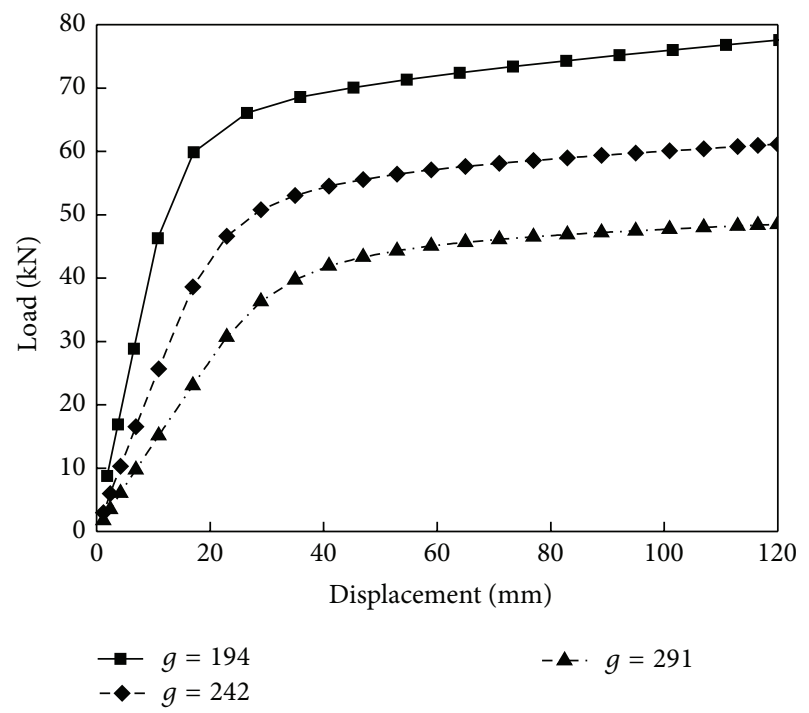

FIGURE 14: Load-displacement hysteretic curves of CFT arch rib considering different value of $g$.

stage as the values of $n$ go up. When the value of $n$ reaches some certain values, all the curves begin to descend. For the long span CFT arch bridge, the stability coefficient usually locates at the interval $[4,5]$, which means that the ratio $n$ belongs to the interval $[0.25,0.2]$. As shown in Figure 16, in this range, the ratio $n$ has little effect on the load-displacement curve of CFT arch rib.

3.3. Transverse Load-Displacement Hysteretic Behavior. Using the calculating model shown in Figure 8(c), the transverse load-displacement hysteretic curve of CFT arch rib is shown in Figure 17. The load-displacement hysteretic curve in the transverse direction of bridge is close to plump

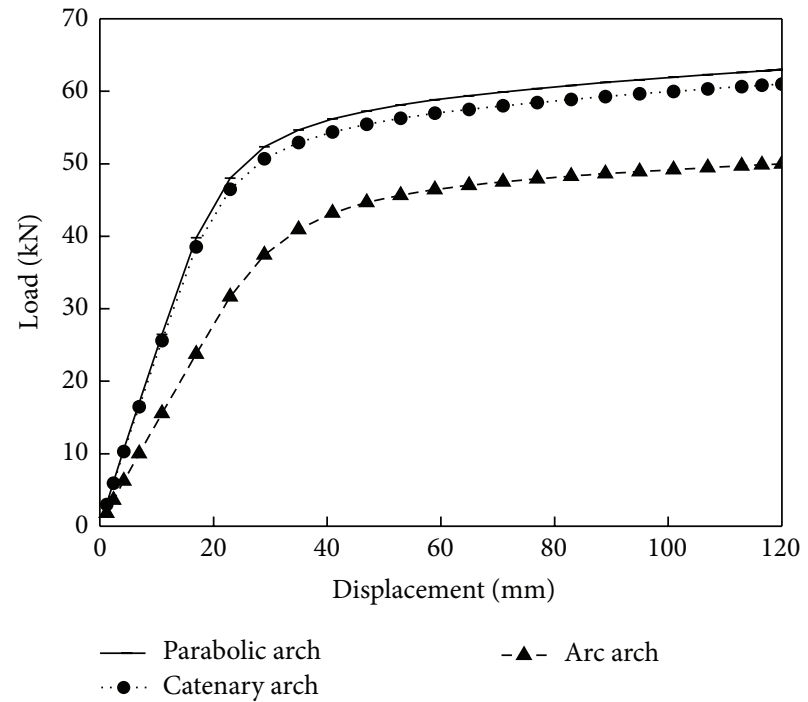

FIGURE 15: Load-displacement hysteretic curves of CFT arch rib considering different arch shape.

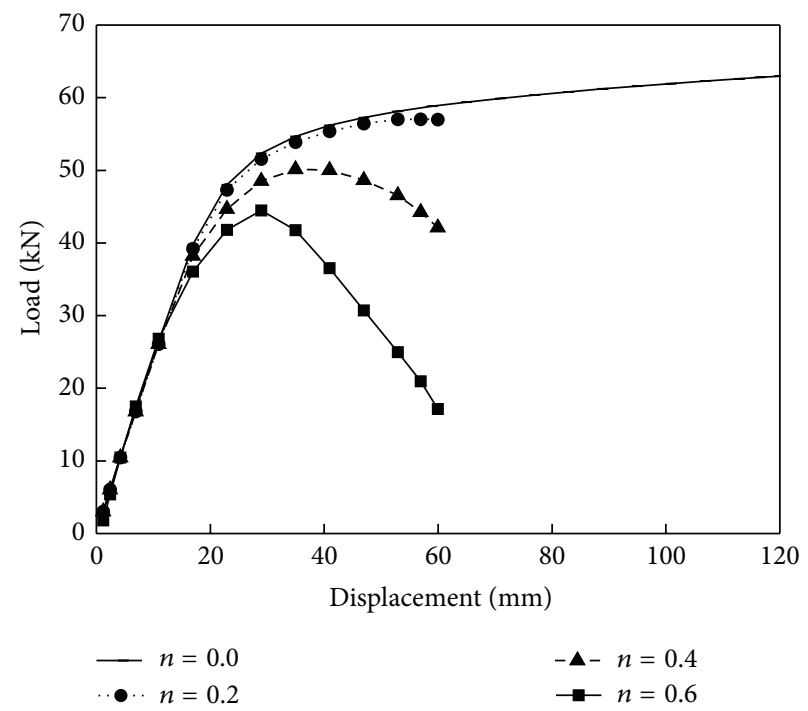

FIGURE 16: Load-displacement hysteretic curves of CFT arch rib considering different value of $n$.

shape. With the similar calculation, we find out that the hysteretic performance is mainly affected by the following factors such as the steel amount ratio of CFT arch ribs $\alpha$, the yield limit of steel material $f_{y}$, the compressive strength of concrete $f_{c u}$, the arch rise span ratio $f$, span tube diameter ratio $g$, and arch shape.

\section{Conclusions}

With the nonlinear finite element model analysis, the hysteretic behaviors of CFT arch ribs under the action of reduplicative load are investigated in this study. The following conclusions are drawn. (i) The load-displacement hysteretic curves of CFT arch ribs in longitude, transverse, and vertical 


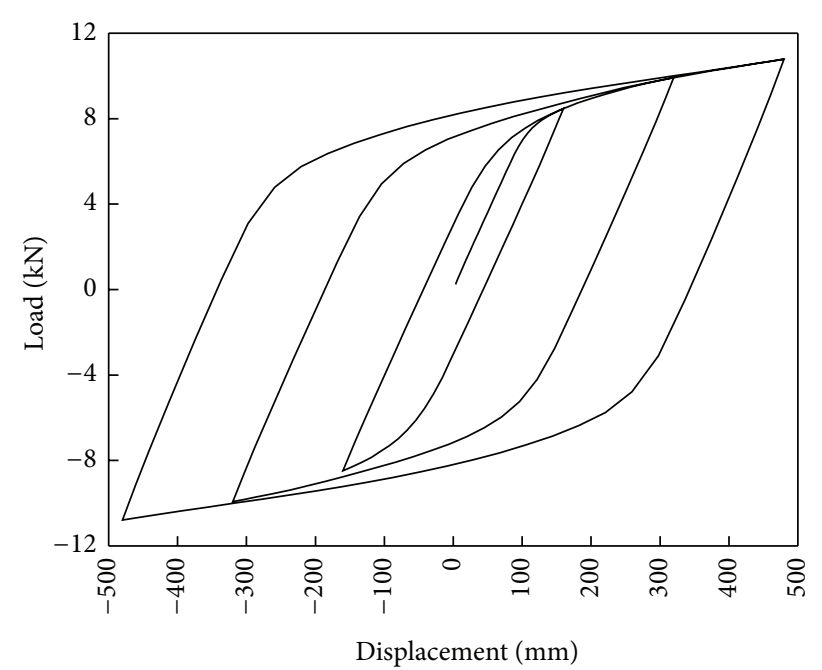

FIgURE 17: Load-displacement hysteretic curves of CFT arch rib in the transverse direction of bridge.

direction of bridges are all close to plump and spindly shape, and these curves have no significant pinch phenomenon. (ii) The moment-curvature hysteretic curves of CFT arch ribs acted by the vertical reduplicative load are similar to the straight CFT component's curves. The load-displacement hysteretic behaviors of CFT arch ribs in longitude and transverse direction of bridge are mainly affected by the steel amount ratio of CFT arch ribs $\alpha$, the yield limit of steel material $f_{y}$, the compressive strength of concrete $f_{c u}$, the arch rise span ratio $f$, span tube diameter ratio $g$, arch shape, and so forth. (iii) The stiffness and load bearing capacity of CFT arch rib increase as the value of the following factors goes up, that is, the steel amount ratio of CFT arch ribs $\alpha$, the yield limit of steel material $f_{y}$, the compressive strength of concrete $f_{c u}$, and the arch rise span ratio $f$, while the span tube diameter ratio $g$ has the opposite effect compared with above factors.

\section{Conflict of Interests}

The authors declare that there is no conflict of interests regarding the publication of this paper.

\section{Acknowledgment}

All the authors of this study thankfully acknowledge the support of this work by Heilongjiang Province Natural Science Foundation (Grant no. E080509).

\section{References}

[1] Q. Wu, M. Yoshimura, K. Takahashi, S. Nakamura, and T. Nakamura, "Nonlinear seismic properties of the Second Saikai Bridge: a concrete filled tubular (CFT) arch bridge," Engineering Structures, vol. 28, no. 2, pp. 163-182, 2006.

[2] B. C. Chen, "Recent advances on design theory of CFST arch bridges," in Proceedings of the IABSE Symposium, pp. 244-245,
Metropolitan Habitats and Infrastructure, Shanghai, China, 2004.

[3] Y. Okamoto, S. Nakamura, H. Tanaka, and Y. Moriya, "Study on steel box girder bridges partly stiffened by CFT arch ribs," Journal of Constructional Steel Research, vol. 70, pp. 28-35, 2012.

[4] L. H. Han, Concrete Filled Steel Tube Structures, Science Press, Beijing, China, 2000, (Chinese).

[5] S. T. Zhong, High-Rise Concrete Filled Steel Tube Structures, Heilongjiang Science and Technology Press, Harbin, China, 1999, (Chinese).

[6] J. F. Hajjar, P. H. Schiller, and A. Molodan, "A distributed plasticity model for concrete-filled steel tube beam-columns with interlayer slip," Engineering Structures, vol. 20, no. 8, pp. 663-676, 1998.

[7] S. B. B. Aval, M. A. Saadeghvaziri, and A. A. Golafshani, "Comprehensive composite inelastic fiber element for cyclic analysis of concrete-filled steel tube columns," ASCE, Journal of Engineering Mechanics, vol. 128, no. 4, pp. 428-437, 2002.

[8] X. L. Lv, G. F. Jin, and X. H. Wu, Nonlinear FEM Theory and Application of Reinforcement Concrete Structures, Tongji University Press, 1997, (Chinese).

[9] W. F. Zhang, Restoring force characteristics research of single level concrete filled steel tube frame [Ph.D. thesis], Harbin Institute of Technology, Harbin, China, 2001, (Chinese).

[10] M. M. Hassan, H. Ramadan, M. Abdel-Mooty, and S. A. Mourad, "Experimental study of CFT bracing connections behaviour under half cyclic loading," in Proceedings of the 11th International Conference on Steel Space and Composite Structures, pp. 225-234, 2012.

[11] J.-W. Hu, Y.-S. Kang, D.-H. Choi, and T. Park, "Seismic design, performance, and behavior of composite-moment frames with steel beam-to-concrete filledtube column connections," International Journal of Steel Structures, vol. 10, no. 2, pp. 177-191, 2010.

[12] J. Cheng, H. Zhu, Y. Ding, S. Zhong, and Q. Zhong, "Stochastic finite-time boundedness for Markovian jumping neural networks with time-varying delays," Applied Mathematics and Computation, vol. 242, pp. 281-295, 2014.

[13] Y. S. Ma, Y. F. Wang, and Z. K. Mao, "Creep effects on dynamic behavior of concrete filled steel tube arch bridge," Structural Engineering and Mechanics, vol. 37, no. 3, pp. 321-330, 2011.

[14] Y. Zeng and Z. Y. Wang, "Self-vibration characteristics analysis of the Yingzhou bridge," Applied Mechanics and Materials, vol. 90-93, pp. 1212-1215, 2011.

[15] J. Cheng, H. Zhu, S. Zhong, F. Zheng, and Y. Zeng, "Finite-time filtering for switched linear systems with a mode-dependent average dwell time," Nonlinear Analysis: Hybrid Systems, vol. 15, pp. 145-156, 2015.

[16] W. F. Zhang, Restoring force characteristics research of single level concrete filled steel tube frame [Ph.D. thesis], Harbin Institute of Technology, Harbin, China, 2001 (Chinese). 


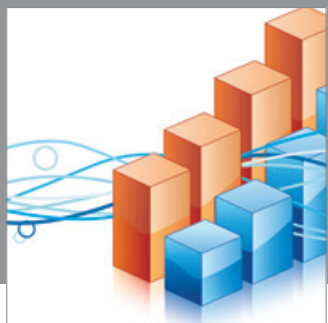

Advances in

Operations Research

mansans

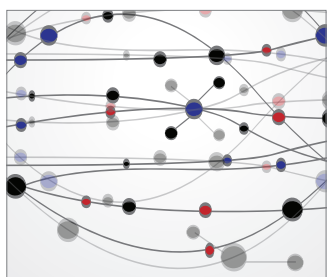

The Scientific World Journal
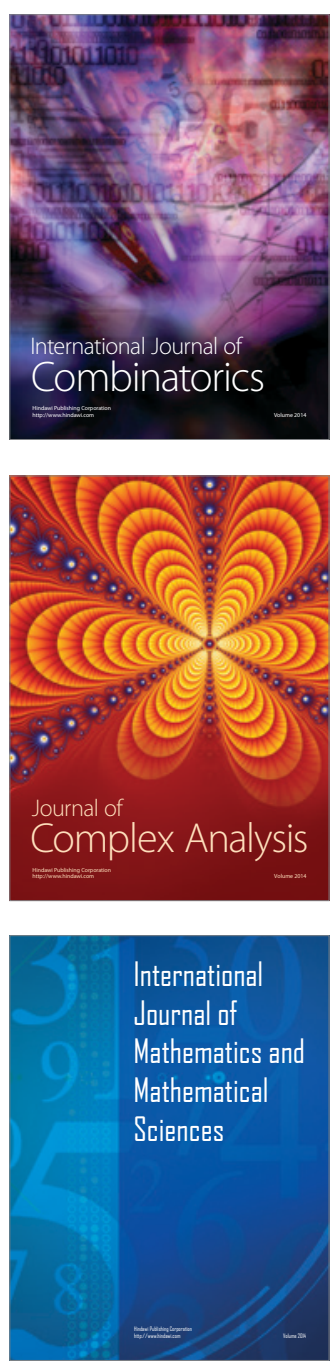
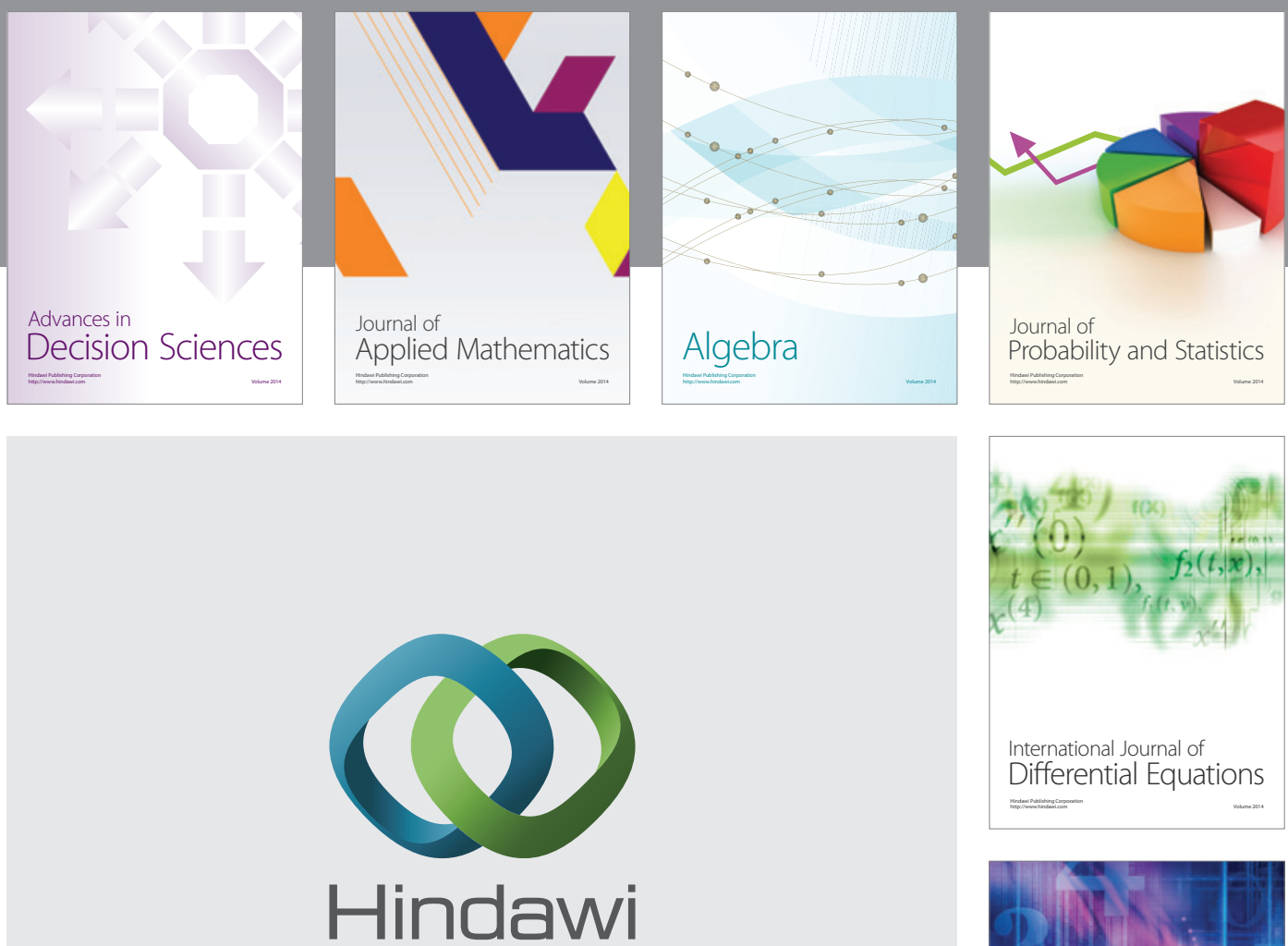

Submit your manuscripts at http://www.hindawi.com
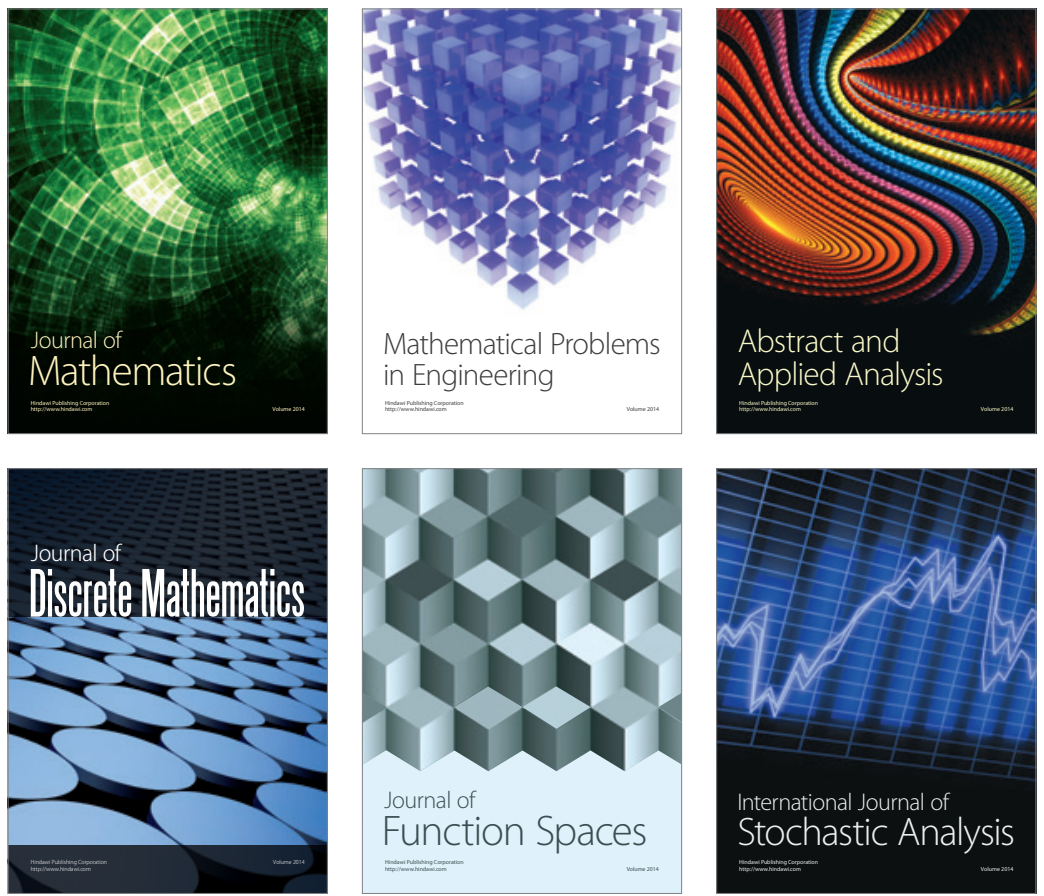

Journal of

Function Spaces

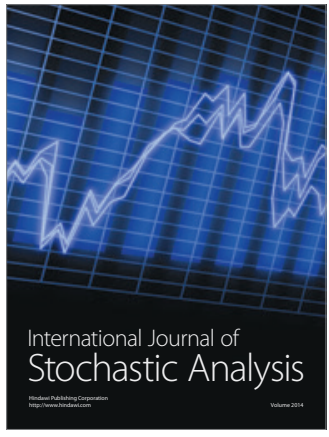

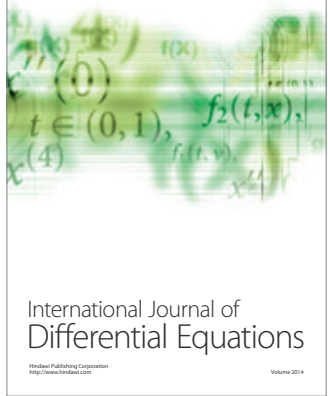
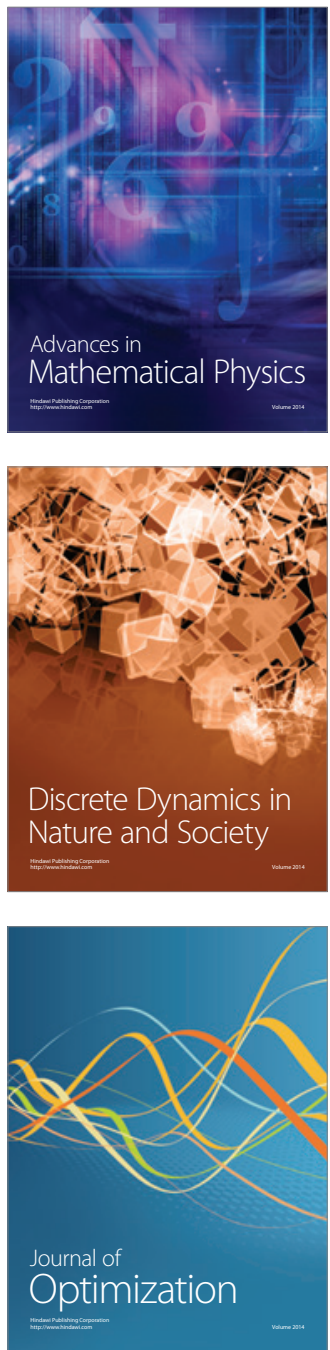